\title{
Decline of Tobacco Smoking Among Medical Specialists at A Spanish University Hospital
}

\author{
Alberto Molina Cabildo ${ }^{1}$, Carmen Díaz Molina ${ }^{1}$, Mohamed Farouk Allam ${ }^{1,2}$ \\ ${ }^{1}$ Department of Preventive Medicine and Public Health, Faculty of Medicine, University of Cordoba, Cordoba, Spain \\ ${ }^{2}$ Department of Community, Environmental and Occupational Medicine, Faculty of Medicine, Ain Shams University, Cairo, Egypt \\ Correspondence: Mohamed Farouk Allam, Department of Community, Environmental and Occupational Medicine, Faculty of \\ Medicine, Ain Shams University. 11566 Abbasia, Cairo, Egypt; E-mail: fm2faahm@ gmail.com and \\ farouk.allam@med.asu.edu.eg; Phone/Fax: +(202) 24346888; Mobile: + (2) 01143559946
}

\begin{abstract}
Background: Several epidemiological studies have shown that the prevalence of tobacco smoking in the Spanish healthcare centres is relatively high. Objective: to assess the current situation of tobacco smoking among medical specialists of Reina Sofia University Hospital (Cordoba, Spain). As a secondary objective we intended to calculate the indirect costs of smoking among medical specialists during the working hours. Materials and Methods: Descriptive cross-sectional study of the medical specialists of Reina Sofia University Hospital. Our survey was conducted using an interview questionnaire that included the following variables: age, sex, medical specialty, smoking habits, tobacco smoking during work hours, time spent on each cigarette, intention to quit smoking and the possibility to participate in a smoking cessation program. Results: A total of 143 medical specialists; 64 women and 79 men were interviewed. About $14 \%$ of participants were former smokers and $10.5 \%$ were current smokers, of whom $67 \%$ wanted to quit smoking. About $73 \%$ of smokers consumed tobacco during the working hours. Most of smokers consumed 2 cigarettes during the working hours. About $60 \%$ of smokers would use a permanent aid program to quit smoking. The hours lost by the smoking habits of medical specialists cause an annual loss of 143.512,96 euros. Conclusions: The study results show that currently there is an increasing awareness of health professionals about the harmful effects of smoking: former smokers have increased, and most of smokers want to quit. Also, they would use a permanent aid program to quit smoking.
\end{abstract}

Keywords: Prevalence, Tobacco, Medical specialist, Reina Sofia University Hospital, Cordoba, quit smoking.

\section{INTRODUCTION}

According to several epidemiological studies, the prevalence of tobacco smoking in the Spanish healthcare centres is relatively high. In a cross-sectional study, conducted in Valencia, about smoking habits among healthcare workers (HCWs) the prevalence rate of smoking reached $37 \%$, and about $57.1 \%$ of smokers had no intention to quit smoking ${ }^{(1)}$. In Teruel, the prevalence of tobacco smoking among HCWs was $29.1 \%$ and only $41 \%$ of smokers accepted to participate in a medical and psychological programme to quit smoking ${ }^{(2)}$. All these studies were published before the Law 28/2005, which prohibited smoking in any work place ${ }^{(3)}$.

In a recent pilot study conducted at Reina Sofia University Hospital of Cordoba, we interviewed 30 medical specialist and 30 nurses. About $13.4 \%$ of the participants were current smokers and only $1.7 \%$ had no intention to quit smoking. All interviewed HCWs knew the current law, which prohibits tobacco smoking in work places, although $11.7 \%$ considered quite complicated its application. About $87.5 \%$ of smokers reported getting out the hospital to smoke during the working hours ${ }^{(4)}$.

It is very important to facilitate treatments for tobacco dishabituation: In 1996, an official report from the World Health Organization (WHO) emphasized on the importance to facilitate treatments for tobacco dishabituation for smokers considering them patients, taking into consideration that tobacco smoking causes a high worldwide morbidities and mortalities, on short and mid-terms ${ }^{(5)}$.

The principal objective of our study is to know the current situation of tobacco smoking among medical specialists of Reina Sofia University Hospital of Cordoba, Spain, with the characteristics of smoking habits and practices of smokers. As a secondary objective we plan to calculate the indirect costs of tobacco smoking of medical specialists during the working hours.

\section{MATERIAL AND METHODS}

Type of study: Cross-sectional study.

Study population: 611 medical specialists of Reina Sofia University Hospital of Cordoba, Spain.

Inclusion criteria: Being a medical specialist working at Reina Sofia University Hospital of Cordoba. Accept to participate in the study.

Exclusion criteria: House officers and Residents or any other category of HCWs. Medical specialists, who are not involved in clinical practices, like management and directors. 
Sample size: The sample size estimated was 136 (approximated to 140) medical specialists, based on: Total number of medical specialists of Reina Sofia University Hospital of Cordoba: 611. Expected proportion: $13 \%$ [4], 95\% confidence interval (0.95)

Sample size was calculated using the statistical package EPIDAT version 3.1.

Ethical Considerations: Approval for this study was obtained by the institutional review board, and Ethical committee. All participants will sign an informed consent after explaining them the objective of the study.

Study variables: Age, sex, specialty, smoking habit, tobacco smoking during working hours, time needed to smoke every cigarette, intention to quit smoking, and the possibility to participate in a smoking cessation program organized by the Andalusian Health Service. Medical specialties were classified into medical and surgical. Medical specialties were anesthesia, clinical pathology, clinical biochemistry, cardiology, GIT, endocrine, hematology, immunology, ICU, internal medicine, family medicine, microbiology, nuclear medicine, preventive medicine, physical medicine and rehabilitation, nephrology, neurophysiology, neurology, oncology, pediatrics, psychiatry, and radio-diagnosis. Surgical specialties were cardiovascular surgery, general and GIT surgery, maxillofacial surgery, thoracic surgery, gynecology and obstetrics, ENT, and orthopedics.

Data collection: The information was collected by an interview questionnaire. This questionnaire included closed questions about the study variables.

Questionnaire: This questionnaire was based on the official questionnaire for tobacco prevention elaborated by the Department of Prevention and Environmental Protection of the University of Cordoba. This questionnaire was modified according to the results of the pilot study [4].

Statistical analysis: Data entry screen was built using Microsoft Excel. Data was checked, coded and entered on the computer. Double data checking was done. First, the following descriptive analysis was done: frequency, percent, mean and standard deviation. Thereafter, comparisons were done using the student's t-test for continuous variables and Pearson's Chi square test for categorical variables. Level of significance was set at $\mathrm{p}<0.05$. Analysis of the data was done using EPIDAT 3.1.

\section{RESULTS}

We interviewed 143 medical specialists, of them $79(55.2 \%)$ were men and $64(44.8 \%)$ were women. The mean age of participants was $47.22 \pm$ 9.9 years (range 29 to 66 ).

Our 143 medical specialists were distributed in 29 specialties; 28 (19.6\%) surgical specialties, and $115(80.4 \%)$ medical specialties. Stratifying the specialties by gender, we realize that in the medical specialties we had $56(48.7 \%)$ women and 59 (51.3\%) men. Meanwhile in the surgical specialties we had $8(28.6 \%)$ women and $20(71.4 \%)$ men, with no statistical significant differences.

The bivariate analysis for age and specialties (medical versus surgical specialties) had a student's t-test of 0.922 with $p$ value of 0.358 (not significant), which indicates that age and specialties are two independent variables.

Of the interviewed medical specialists, about $14 \%$ were ex-smokers and $10.5 \%$ were current smokers, of whom about $53.3 \%$ wanted to quit smoking (Figure 1).

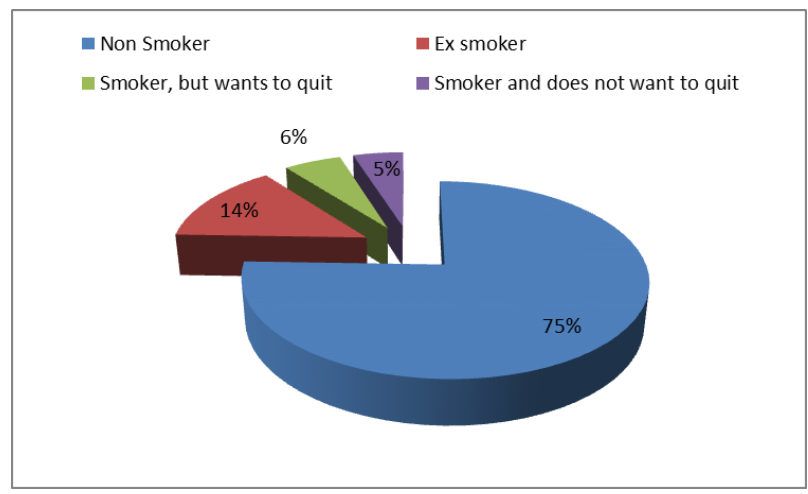

Figure (1): Smoking habits of interviewed medical specialists at Reina Sofia University Hospital.

Comparing smoking habits of medical specialists according to their specialty, we found that medical specialties smoked less than surgical specialties ( $9.6 \%$ versus $14.3 \%$ ), in addition they had more intention to quit smoking (6.1\% versus $3.6 \%)$ without statistical significant differences (Table 1). 
Table (1): Comparative analysis of smoking habits of interviewed medical specialists at Reina Sofia University Hospital according to their specialties.

\begin{tabular}{|l|c|c|c|}
\hline \multicolumn{1}{|c|}{ Smoking habit } & $\begin{array}{c}\text { Medical } \\
\text { Speciality }\end{array}$ & $\begin{array}{c}\text { Surgical } \\
\text { Speciality }\end{array}$ & P value \\
\hline Non-smoker & $87(75.7 \%)$ & $21(75 \%)$ & \\
\cline { 1 - 3 } Ex-smoker & $17(14.8 \%)$ & $3(10.7 \%)$ & \\
$\begin{array}{l}\text { Smoker, but wants to } \\
\text { quit }\end{array}$ & $7(6.1 \%)$ & $1(3.6 \%)$ & \multirow{2}{*}{0.40} \\
\cline { 1 - 3 } $\begin{array}{l}\text { Smoker and does not } \\
\text { want to quit }\end{array}$ & $4(3.5 \%)$ & $3(10.7 \%)$ & \\
\cline { 1 - 3 } Total & $115(100 \%)$ & $28(100 \%)$ & \\
\hline
\end{tabular}

Of the 15 current smokers, 11 (73.3\%) medical specialists admitted smoking during the working hours. On asking about the number of cigarettes smoked during the working hours, most of them (8 of 11) smoked 2 to 4 cigarettes. Regarding the time needed to smoke each cigarette, more than half of them $(54.6 \%)$ reported that it was from 4 to 5 minutes (Table 2).

Table (2): Estimated time for smoking every cigarette by medical specialist of Reina Sofia University Hospital.

\begin{tabular}{|c|c|c|}
\hline Minutes/cigarette & Frequency & Percentage \\
\hline 3 & 1 & 9.1 \\
\hline 4 & 2 & 18.2 \\
\hline 5 & 4 & 36.4 \\
\hline 7 & 1 & 9.1 \\
\hline 8 & 1 & 9.1 \\
\hline 10 & 1 & 9.1 \\
\hline 15 & 1 & 9.1 \\
\hline Total & 11 & 100 \\
\hline
\end{tabular}

On asking the 15 current smokers about intention to quit smoking, $10(66.7 \%)$ of them wanted to do that. Only $9(60 \%)$ of the current smokers reported their acceptance to use a permanent program for tobacco dishabituation organized by the Andalusian Health Service.

The small proportion of smokers among medical specialists of Reina Sofia University Hospital of Cordoba called us to investigate the justification to elaborate a permanent program for tobacco dishabituation.

According to our results $10.5 \%$ of the interviewed physicians are current smokers, which indicates that about 64 medical specialists of Reina Sofia University Hospitals of Cordoba are current smokers, taking into consideration that we have a total of 611 medical specialists. Of the 64 possible current smokers, about $67 \%$ will have intention to quit smoking, and $60 \%$ will use a program for tobacco dishabituation.

The results of the current study indicate that the mean time utilized by the medical specialists to smoke is 6.45 minutes per cigarette and they smoke 3.45 cigarettes during the working hours. These data indicate that every smoker losses about 22.25 minutes of the daily working hours; 85.3 hours lost per year.

Taking into consideration that every medical specialist works 1725 hours yearly and earns a year salary, without incentives, of $48,987.36$ euros, it is estimated that the loss reaches $2,242.39$ euros by every smoker. Thus and accepting that $10.5 \%$ of the medical specialists of Reina Sofia University Hospital of Cordoba are smokers (total 64), the total money lost would be $143,512.96$ euros.

\section{DISCUSSION}

The current study aimed mainly to study the prevalence of smoking among medical specialists of Reina Sofia University Hospital of Cordoba, and secondary to estimate the indirect cost of smoking among medical specialists during the working hours.

In our study, the prevalence of smoking among medical specialists was $10.5 \%$. This figure is quiet low to what was reported in other previous studies conducted in different health centres in Spain ${ }^{(4,5)}$. A study was conducted in Asturias showed that $31.8 \%$ of healthcare workers were smokers ${ }^{(7)}$. In Valencia, the prevalence of smoking was $37 \%^{(1)}$, meanwhile in Teruel was $29 \%^{(2)}$.

All these studies were conducted before Law 28/2005 (26 $6^{\text {th }}$ of December 2005) of the Spanish Ministry of Health and Consumption, about limitation of buying and consumption of tobacco, aimed at for promotion of the health of the general population. This legalization supports, in case of conflict, the health of non-smokers, and prohibits smoking in working places ${ }^{(3)}$.

In Spain, the next laws appeared over the last 20 years; Royal Law 192/1988 (4 ${ }^{\text {th }}$ of March 1988 ) and Law $28 / 2005$ (26 $6^{\text {th }}$ of December 2005). The law 42/2010 ( $30^{\text {th }}$ of December 2010), known as the new law against tobacco smoking, included important measures like prohibition of smoking in any zone/area of collective use, stores, bars and restaurants, not on open air, together with the 
prohibition in some open zones/areas because they are covered ${ }^{(3,4)}$.

A recent study conducted in 2014 by the Tobacco Section of the Spanish Society of Chest Diseases and Thoracic Surgery showed an important decline of the number of smokers among healthcare workers. Only $11.7 \%$ of the participants in that study were current smokers and up to $41.3 \%$ were ex-smokers ${ }^{(8)}$. The results of the current study and the low prevalence of smoking among medical specialists of Reina Sofia University Hospital of Cordoba, indicate that the legal measures adopted by government, first prohibiting smoking in work places, and later in public places, have clearly decreased the number of smokers.

Regarding the intention to quit smoking, in our study about two-third of current smokers wanted to do that. This proportion is higher than that reported in previous studies: in Valencia $57.1 \%$ of smokers wanted to quit smoking ${ }^{(1)}$ and in Asturias nearly half of them ${ }^{(7)}$.

In addition, we found that $60 \%$ of our smoking medical specialists will use a permanent smoking cessation program organized by the Andalusian Health Service, meanwhile in Teruel only $41 \%$ of smokers will accept medical and psychological support to quit smoking ${ }^{(2)}$.

In a study conducted in Bilbao about the effectiveness of tobacco cessation program, it was shown that a general, simple and easy intervention at work place supervised by a specialist and including nicotine patches, is very effective to quit smoking on short and long term. This study reported that 9 smokers will need to be treated to achieve tobacco abstinence during 12 months ${ }^{(9)}$.

A recent cross-sectional study conducted by the Spanish Society of Chest Diseases and Thoracic Surgery concluded that more than half of healthcare workers interviewed (about 55\%) utilized psychological consultation and pharmacological prescriptions when helped their smokers' patients to quit smoking, because they considered them effective and cheap measures ${ }^{(8)}$.

Healthcare costs and costs related to lower productivity because of smoking-associated diseases are the main costs of smoking. Other costs for the companies include working hours lost during smoking, insurance against fairs and costs related to cleaning of work place because of smoke and ashes ${ }^{(9)}$.
According to the National Committee for Tobacco Prevention, every smoker worker in Spain costs his company yearly about 1700 euros. This calculation includes from work absenteeism till cleaning work place because of the smoke produced by cigarettes. Different studies compared the costs of having a smoker and non-smoker worker ${ }^{(10)}$.

A study conducted on American Veterans showed the tobacco consumption was responsible for an important proportion of hospitalization and work absenteeism, especially in males ${ }^{(11)}$. Also, it was noted that smokers were more susceptible for many of diseases and had poorer health compared with non-smokers. This could be objectively observed by the higher prevalence of work absenteeism among smokers. Smokers are at high risk for cancer, bronchitis, emphysema, cardiovascular diseases and embolism, in addition they more susceptible for common cold and influenza $^{(12)}$.

In our study, the costs of lost working hours because of smoking was 2,242.39 euros for every smoker, which indicate more cost for every medical specialist smoker if we considered other aspects like work absenteeism. This could justify the cost-effectiveness of the implantation of a plan for tobacco cession.

According to a program to quit smoking conducted by Barcelona Medical Syndicate ${ }^{(6)}$; the costs for implementation of the program were 68,526.03 (informative materials, administrative personnel, and supportive treatments). If we add a medical specialist in tobacco dishabituation and a nurse, the yearly costs of their salaries will be $75,781.65$ euros. The total costs of the program for tobacco dishabituation will rise to $144,307.68$ euros.

Although a program for tobacco cession could not be cost effective in the first year, this cost-effectiveness will improve markedly from the second year. If two-third of medical specialists willing to quit smoking and achieved that we will save yearly 96,422.77 euros. Also, the main cost of a program for tobacco cession is the salaries of the healthcare workers of that program $(<76,000$ euros), and if the same clinic offers the same service for other medical and non-medical workers of Reina Sofia University Hospital, like nurses, assistant nurses, orderlies, doormen, and 
administrative workers, the cost-effectiveness of the program will be much higher.

\section{CONCLUSION}

Our results indicate the any activity that could decrease the proportion of smokers will be very positive, especially if we consider working hours lost because of smoking and that most of medical specialists smokers have the intention to quit this bad habit. A program for tobacco cession will be cost-effectiveness to recuperate these lost working hours, and attain better health for all healthcare workers.

\section{REFERENCES}

1- Larnia Sánchez A, Sánchez González JI, Aicart Bort MD, Almela Tejedo T, Brotons Muntó F, González Aliaga J, Jorro Llagaría A, López Pérez F, Mallen Navarro N, Mascarós Balaguer E, Montejano Juan J, Serrano Selva EM (2001): Prevalencia del tabaquismo entre el personal sanitario de los Centros de Salud de la Comunidad Valenciana y su actitud ante el problema. Sociedad Valenciana de Medicina Familiar y Comunitaria 2001. Avialable at: http://www.svmfyc.org/files/Grupos\%20de\%20T rabajo/Abordaje\%20Tabaquismo/Tabaquismo.pd $\mathrm{f}$

2- Vidal Tolosa A, Marcos Díaz Hurtado M, Prieto Andrés P (2002): Prevalencia del consumo de tabaco en personal hospitalario. Boletín Oncológico del Área Sanitaria de Teruel, 19(2):11-15.

3- Texto Refundido De La Ley 42/2010, De 30 De Diciembre, Y La Ley 28/2005, De 26 De Diciembre, De Medidas Sanitarias Frente Al Tabaquismo Y Reguladora De La Venta, El Suministro, El Consumo Y La Publicidad De Los Productos Del Tabaco (2012): http:// www. ub. edu/ ossma/ wp-content/ uploads/ 2016/ 02/ llei282005- 422010.pdf

4- Farouk Allam M, Quintano Reina C, Angulo Lucena R, Serrano del Castillo A, Quintano Jiménez J (2014): Hábito tabáquico entre médicos y enfermeros de Córdoba. Congreso Nacional SEMERGEN Bilbao 2014. congresonacionalsemergen.com/

5- Farouk M, Díaz-Molina C, Serrano A, Barranco JL, Torcello R, Fernández-Crehuet R (2006): El tabaco: la epidemia del siglo veinte. Medicina Preventiva, 12(1):28-36.
6- Hormigo Amaro J, García-Altés A, López MJ, Bartoll X, Nebot M, Ariza C (2009): Análisis de coste-beneficio de un programa de prevención del tabaquismo en escolares. Gac Sanit, 23(4):311-4.

7- Rodríguez García E, Valderrey Barbero J, Secades Villa R, Vallejo Seco G, Fernández Hermida JR, Jiménez García JM, Díaz González T, García Rodríguez O (2004): Consumo y actitudes sobre el tabaco entre el personal sanitario del Principado de Asturias (España). Trastornos Adictivos, 6(4):234-9.

8- El consumo de tabaco disminuye drásticamente entre los profesionales sanitarios españoles (2014): Programa Integrado de Investigación en Tabaquismo de la Sociedad Española de Neumología y Cirugía Torácica (SEPAR). Julio 2014. Available at: https:// www. menarini. es/ images/ notasprensa/ documentos/ 20140708 NPEstudio Tabaquismo _SEPAR_ Menarini.pdf

9- Rodríguez-Artalejo $F$, Lafuente Urdinguio $P$, Guallar-Castillón P, Garteizaurrekoa Dublang P, Sáinz Martínez O, Díez Azcárate JI, Foj Alemán M, Banegas JR (2003): One year effectiveness of an individualised smoking cessation intervention at the workplace: a randomized controlled trial. Occup Environ Med., 60:358-63.

10-Evaluación del Control del Tabaquismo sobre los costes empresariales y sanitarios (2009): Informe del Comité Nacional para la Prevención del Tabaquismo.. Available at: http:// www. who. $\mathrm{int} / \mathrm{fctc} /$ reporting/ party_reports/ spain_annex5_ evolution_costs_business_health.pdf

11- Robbins AS, Fonseca VP, Chao SY, Coil GA, Bell NS, Amoroso PJ (2000): Short term effects of cigarette smoking on hospitalisation and associated lost workdays in a young healthy population. Tob Control, 9(4):389-96.

12-Raaijmakers T, van den Borne I (2003): Relación coste-beneficio de las políticas sobre consumo de trabajo en el lugar de trabajo. Rev Esp Salud Publica, 77(1):97-116. 